\title{
Hepatocellular carcinoma in pregnancy
}

Dear Sir,

Hepatocellular cancer constitutes $90 \%$ of all primary liver cell cancers worldwide. ${ }^{[1]}$ There is high prevalence of hepatitis B virus carrier in eastern Asia and Sub-Saharan Africa (5\%-10\%), ${ }^{[1]}$ and this has been implicated as a major causative factor. Other etiological factors include alcoholism and prolonged oral contraceptive usage, ${ }^{[2]}$ which have been linked to liver cirrhosis.

Primary liver cancer in pregnancy is very rare; ${ }^{[2]}$ however, positive association has been previously established, ${ }^{[3,4]}$ with risk increasing proportionately with parity. ${ }^{[4]}$

Prognosis of primary liver cancer in pregnancy is very poor. Maternal and fetal losses have remained almost $100 \%$ in reported cases. In a series from IleIfe, Nigeria, 5 out of the 6 women who reported with hepatocellular carcinoma in pregnancy and postpartum period died after an average of 20 weeks of illness. ${ }^{[5]}$ It is noteworthy that 5 of the 6 women presented in the postpartum period after a normal delivery, showing that Nigerian women with hepatocellular carcinoma may carry pregnancy to term and have a normal delivery. ${ }^{[5]}$ We report a case of pregnancy associated with primary liver cell carcinoma in which the mother had a spontaneous vaginal delivery of a live baby and both mother and baby were alive 6 months postpartum.

A 40-year-old female farmer, gravida 9 para, presented at our facility with a 7-month history of right hypochondrial pain that was gradual in onset, progressive, dull and persistent. The pain was not relieved by analgesics, food or posture. The pain radiated to the back and lower part of the chest bilaterally. There was a history of anorexia, easy satiety and weight loss. There was neither any history of jaundice, body itching, joint swelling or pain nor any history of bleeding from any orifice. There were no cardiorespiratory or urogenital symptoms. There was no history of blood transfusion or surgery, and she had not been on any regular medications. There was no history suggestive of diabetes mellitus, hypertension, cigarette smoking or alcohol ingestion. She did not store grains at home and had no contact with chemicals or ionizing radiation. She had delivered 7 times, with 1 miscarriage; 5 children are alive now, and the last childbirth was 3 days before presentation. She had a normal delivery of a live baby girl who was asphyxiated at birth and had to be managed at the special baby care unit (SBCU) of our hospital.

Clinical signs included wasting, soft silky hair, jaundice, dehydration, moderate pallor and palmer erythema. No parotid enlargement, pedal swellings or lymphadenopathy was found. Her pulse was $83 /$ min, regular; she had normal blood pressure, viz., $120 / 80 \mathrm{mmHg}$, with soft heart sounds $\mathrm{S}_{1}$ and $\mathrm{S}_{2}$. Chest examination was unremarkable. Abdomen was distended with distorted contour in the upper half; there were visibly distended anterior abdominal wall veins draining away from the umbilicus. Liver was enlarged $16 \mathrm{~cm}$ below the xiphisternum and $10 \mathrm{~cm}$ below the right costal margin with a span of $20 \mathrm{~cm}$. The liver was hard, nodular with irregular edge, mild tenderness and had a bruit over it. Spleen was not palpably enlarged, and there was no demonstrable ascites. Rectal and vaginal exams were unremarkable. An initial diagnosis of primary liver cell carcinoma was made. Laboratory evaluation revealed packed cell volume of $25 \mathrm{~g} / \mathrm{dL}$, WBC of 9400 cells/dL with neutrophils - $67 \%$, eosinophils - $2 \%$ and lymphocytes $-30 \%$. Platelet count was $435 \times 10^{9} / \mathrm{L}$. Prothrombin time was deranged 3 times the normal value and Kaolin Cephalin Clotting Time (KCCT) deranged 4 times the normal value. Renal functions showed mild elevation of creatinine to $200 \mathrm{uml} / \mathrm{L}$. Liver function test showed normal transaminases and serum bilirubin. Total protein was low, at $44 \mathrm{~g} / \mathrm{L}$, with albumin of $28 \mathrm{~g} / \mathrm{L}$ and globulin of $16 \mathrm{~g} / \mathrm{L}$. Hepatitis B surface antigen (HBsAg) was 
positive, alpha fetoprotein was high $(>400 \mathrm{ng} / \mathrm{mL})$, and her serum was nonreactive to HIV. Chest X-ray was normal. Abdominal ultrasound scan showed a huge hepatomegaly with cystic degeneration and probe tenderness. Pelvic Ultrasonography (USS) showed a bulky uterus with a thin film of fluid. Liver biopsy showed a tumor growing in cords, trabeculae and nests with occasional glandular pattern. The tissue was composed of cells having hyperchromatic nuclei with scanty amount of amphophilic cytoplasm arranged in 3-4-cell thick plates. The diagnosis of primary liver cell carcinoma was thus confirmed.

She was managed with analgesia and nutritional advice and was also adequately counseled. Her baby did well at the SBCU and was discharged. The mother was also discharged to be followed up at the GastroIntestinal Tract (GIT) clinic. She has remained stable 6 months after discharge.

Hepatocellular carcinoma is rarely associated with pregnancy; and when it does, the prognosis is not very good for both the mother and the baby. In a study reported from Taiwan, of the 3 cases of pregnancy complicated by primary hepatocellular carcinoma seen over a 3 -year period, all the 3 women and 1 fetus died. ${ }^{[6]}$ The only case we saw reported from Nigeria was also lost to hepatic encephalopathy before delivery. ${ }^{[7]}$

Our patient presented with the classical features of primary liver cancer. Diagnosis was made from clinical and ultrasound findings and confirmed on histological examination of the liver biopsy specimen. Past hepatitis from the type B hepatitis virus, which has been strongly implicated, was confirmed in our patient. The fact that our patient was not aware of her HBsAg status may mean that she had a subclinical infection with the virus.

The fact that our patient presented 3 days after delivery meant that she had minimal symptoms of the malignancy during the gestation period or at least the symptoms were masked by the pregnancy. The gynecologist reported an uneventful pregnancy even though an abnormal abdominal (liver) mass was noted in the upper abdomen, which remained after delivery. Silent primary carcinoma complicating pregnancy has been reported previously, though both cases reported had had previous hepatic resection for the tumors. ${ }^{[8,9]}$

It is remarkable that our patient and the baby survived the pregnancy and even 6 months after delivery though the baby was asphyxiated at birth, considering that in some reports with facilities for early diagnosis, mothers and fetuses could not be saved. ${ }^{[6]}$ There are other reports, however, in which both mother and baby were saved..$^{[8,9]}$ The liver enzymes were only slightly elevated in our patient; this is in keeping with previous findings. ${ }^{[6]}$

Estrogens stimulate hepatic growth, alter liver metabolism, and endogenous hormones may contribute to liver cancer development. ${ }^{[4]}$ Estrogen levels rise enormously in pregnancy. The fact that our patient engaged in active farming activities even during pregnancy and the fact that aerobic exercise can affect the hypothalamic-pituitary-gonadal axis, thus leading to a reduction in estrogen and progestogen release from the ovaries, ${ }^{[10]}$ could probably explain why our patient had it easy with the pregnancy. We could not assay the hormones to confirm this as the patient was referred to us after delivery.

Careful evaluation of pregnant women, especially when abnormal masses are seen, abdominal sonography, magnetic resonance imaging (MRI), together with evaluation for maternal serum alpha fetoprotein and amniotic fluid alpha fetoprotein if the facilities are available, should help identify pregnant women with liver cancer for optimal management of the mother and the baby.

Sani B. Garko, O. S. David, Tasiu Mohammed, M. S. Isah, A. G. Bakari, A. O. Oguntayo ${ }^{1}$, M. S. Shehu' ${ }^{2}$, S. M. Aminu ${ }^{3}$

\author{
Departments of Medicine, ${ }^{1}$ Obstetrics and \\ Gynaecology, ${ }^{2}$ Pathology, ${ }^{3}$ Haematology and Blood \\ Transfusion, Ahmadu Bello University Teaching \\ Hospital, Shika, Zaria \\ Address for correspondence: Dr. Sani B. Garko, \\ Department of Medicine, Ahmadu Bello University \\ Teaching Hospital, Shika, Zaria. \\ E-mail: Sbgarko@yahoo.com
}

DOI: $10.4103 / 1596-3519.59588$

\section{References}

1. Trichopoulos D. Etiology of primary liver cancer and the role of steroidal hormones (editorial). Cancer Cases and Controls 1992;3:3-5.

2. Egwuatu VE. Primary hepatocarcinoma in pregnancy. Trans Royal Soc Trop Med Hyg 1980;74:793-4.

3. La vecchia C, Altieri A, Franceschi S, Tavani A. Oral contraceptives and cancer: An update. Drug Safety 2001;24:741-54

4. Hsing AW, McLaughin JK, Hoover RN, Co Chien HT, Blot W], Fraumeni JF Jr. Parity and primary liver cancer among young women.] Natl Cancer Inst 1992;84:1118-9.

5. Ndububa DA, Makinde ON, Ojo OS, Olasode B], Adetiloye VA, Famurewa OC, et al. Case report: Hepatocellular carcinoma in pregnancy and postpartum period: A study of 6 cases in Nigerian women. Niger ] Clin Pract 2004;7:46-9.

6. Wang LR, Jeng C], Chu JS. Pregnancy associated 
hepatocellular carcinoma. Obstet Gynecol 1993;81:811-3.

7. Umeora OU, Egwuatu VE, Esike CO. Maternal mortality following primary liver cell cancer in pregnancy in a Nigerian. Ann Afr Med 2006;5:163.

8. Moon HK, Ta-Jung L. Silent primary carcinoma of the liver complicating pregnancy: Report of a case. Obstet
Gynaecol 1965;25:848-52.

9. Jerome HC, Lorraine CK, Abraham ER. Uncomplicated pregnancy following oral contraceptive-induced liver hepatoma. Obstet Gynaecol 1978;52:28s-9s.

10. Wolman RL. ABC of sports medicine: Osteoporosis and exercise. Br Med ] 1994;309:400. 